\title{
Cadernos de Processos e Práticas em Hotelaria Hospitalar da Rede de Hospitais de Universitários Federais
}

\section{INTRODUÇÃO}

A Empresa Brasileira de Serviços Hospitalares, vinculada ao Ministério da Educação, é responsável pela gestão de 40 Hospitais Universitários Federais (HUF), e atua com o intuito de modernizar a gestão dos hospitais. Possui, aproximadamente, 8,5 mil leitos ativos.

Os serviços de apoio respondem pela segunda folha de pagamento mais cara de um hospital ('). Além disso, esses serviços, em especial aqueles relacionados à hotelaria hospitalar, têm se configurado de extrema importância uma vez que oferece suporte para as atividades assistenciais e contribui diretamente para a recuperação dos pacientes. $\mathrm{Na}$ Rede a hotelaria é responsável pelos serviços de higienização hospitalar, processamento de roupa e gestão do enxoval, produção e distribuição de dietas, gerenciamento de resíduos e gerenciamento de ambulâncias.

A partir da análise de documentos e visitas técnicas aos HUFs da Rede foi identificado que os processos de hotelaria hospitalar são aplicados com práticas bastantes variáveis entre os hospitais, o que dificulta ações de planejamento, programação, padronização, execução, avaliação e monitoramento, bem como impacta na qualidade assistencial, segurança de pacientes (usuários do SUS), trabalhadores e comunidade.

\section{OBJETIVO}

Os Cadernos de Processos e Práticas em Hotelaria Hospitalar $\left({ }^{2}\right)$ objetivam a padronização das entregas dos serviços de hotelaria hospitalar nas filiais em um mesmo nível de serviço, a partir da reorganização e reestruturação dos processos com base nas melhores práticas de execução definidas pela Rede.

\section{MATERIAIS E MÉTODOS}

A elaboração dos Cadernos teve início em abril de 2015 e contou com mais de 120 reuniões presenciais, visita a 5 hospitais de diferentes Unidades da Federação, 635 questionários respondidos em plataforma online, fóruns de discussão com participações de técnicos reconhecidos da literatura especializada nacional e a contribuição de todos os hospitais.

0 método teve como base a Gestão por Processos.

Os Cadernos possuem como escopo quatro (4) grupos de serviços, totalizando 11 processos.

Figura 1: Escopo de Atuação.

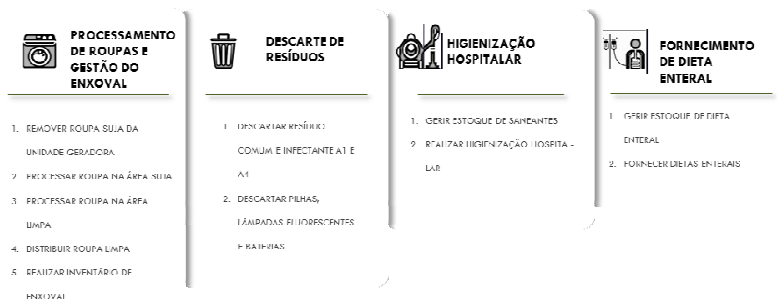

Figura 2: Exemplo de processos do grupo Processamento de Roupa e Gestão do Enxoval.
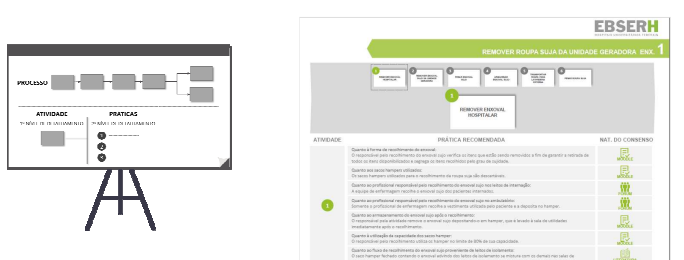

\section{RESULTADO E DISCUSSÃO}

As macroetapas do projeto envolveram:

Figura 3: Macroetapas.

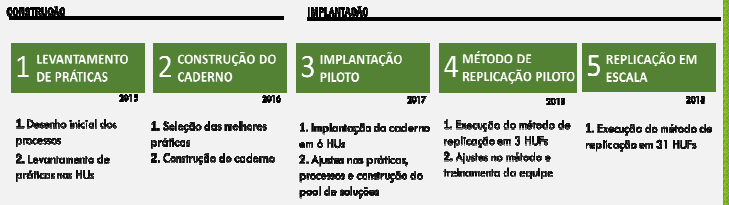

A partir do projeto piloto em seis (6) HUFs - onde a imersão era de 4 semanas - foi desenvolvido o método de replicação enxuto, com 10 dias de imersão sendo possível elaborar cronograma para implantação dos Cadernos em 100\% da Rede Ebserh no ano de 2018.

Figura 4: Método de replicação em escala.

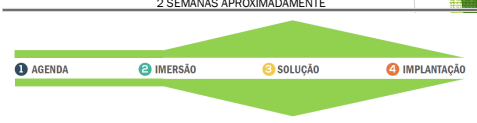

Resultados e ganhos na hotelaria hospitalar:

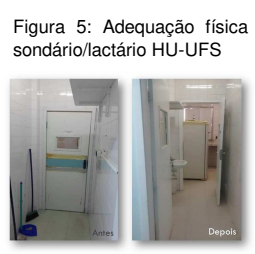

Figura 8: Organização de Figura 8: Organização de
expurgos e DMLs MEJC-UFRN

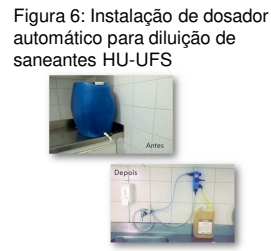

Figura 9: Padronização saco hamper HUCAM-UFES
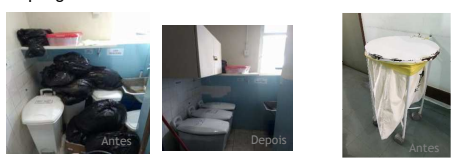

Figura 11: Em todos os HUs em média $90 \%$ das lixeiras infectantes continham lixo comum. Foi revisado a enfermagem.

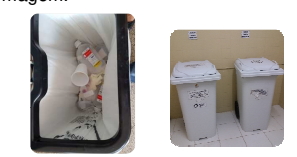
quantidade das lixeiras e centralização nos postos de

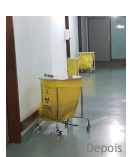

Figura 12: Checkilist de avaliaçâao Figura 12: Checklist de avaliação da qualidade da
limpeza terminal das enfermarias HUOL-UFRN

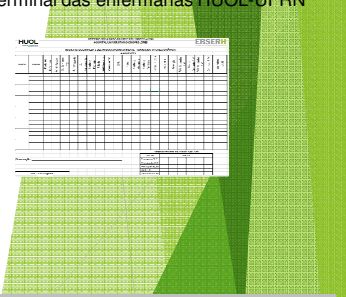

\section{CONCLUSÃO}

Em 2018 ocorreu a implantação dos Cadernos de Processos e Práticas em Hotelaria Hospitalar em $100 \%$ dos hospitais da Rede Ebserh.

Com a implantação, nos seis (6) hospitais piloto, obteve-se a melhoria da qualidade da assistência e redução de riscos em 43.000 internações e 22.500 cirurgias por ano. Além disso, proporcionou-se melhor atendimento em 1,3 milhões de consultas e 3,37 milhões de exames anuais. Em termos de economicidade gerou uma redução anual de mais de $R \$ 3,4$ milhões.

A projeção para a Rede dos ganhos obtidos resulta numa economia estimada de $\mathbf{R} \$ 22,7$ milhões por ano.

A iniciativa é inovadora, pois foi desenvolvido um método de construção coletiva, transformação da realidade (por meio da revisão de processos) em ciclos contínuos, e de replicação em escala para os HUFs da Rede. 